Research Article

\title{
3D Culture Histology Cryosectioned Well Insert Technology Preserves Structural Relationship Between Cells and Biomaterials for Time-Lapse Analysis of 3D Cultures.
}

André Marc Charbonneau ${ }^{1}$

Ahmed Al-Samadi ${ }^{2}$

Tuula Salo ${ }^{2}$

Simon D. Tran ${ }^{1}$

1Dentistry, McGill University, Montréal, Canada

20ral and Maxillofacial Diseases, University of Helsinki, Helsinki, Finland

Correspondence: Professor Simon D. Tran, Dentistry, McGill University, 3640 University Street, H3A 0C7, Montréal, Canada.

E-mail: simon.tran@mcgill.ca

Keywords: 3D Culture, Biomaterial, Histology, Salivary Gland, Well Insert

Abbreviations: TBST, $1 \mathrm{X}$ TRIS Buffered Saline/0.1\% Tween 20; CT, Computed Tomography; MRI, Magnetic Resonance Imaging; OCT, Optimal Cutting Temperature (Cryostat Tissue Embedding Chemical); LSM, Light Sheet Microscopy; PBS, Phosphate Buffered Saline; IHC, Immunohistochemistry. 


\begin{abstract}
When performing histology of softer biomaterials, aspiration disrupts the cellular and molecular location information. This study aims to develop a cryosectionable well insert able to preserve the biomaterial and cell's original three-dimensional (3D) conformation from the well to histology analysis. The well insert is composed of a paraffin coated gelatine pill. Within the coated capsule human epithelial cell line (NS-SV-AC) is cultured in Matrigel, GrowDex, Myogel, Myogel + GrowDex, or cell culture media for 14 days. At 0 and 14 days, the samples are frozen in liquid nitrogenand cryotome creates sections. The slides are stained by Sirius Red and immunohistochemistry using antibodies human collagens I-V and human Ki-67. Sirius Red shows pink shades of biomaterials and best cellular vertical distribution throughout the sagittal section of the well is with Matrigel, GrowDex, and Myogel + GrowDex; in Myogel and media, the cells sink. For collagen protein expression, only Matrigel induces a notable difference while in the other materials, collagen staining is weak or difficult to distinguish from endogenous collagens. Ki-67 expression is maintained over time. The 3D-Cryo well insert provides a new timelapse histology perspective of analysis for liquid or gel cultures that maintains cells and macromolecules in their unaltered in-well configuration.
\end{abstract}

\title{
Keywords:
}

Well Insert, Salivary Gland, Collagen Synthesis, 3D Culture, Biomaterials, Histology

\section{Abbreviations:}

TBST: 1X Tris Buffered Saline/0.1\% Tween 20.

CT: Computed Tomography

MRI: Magnetic Resonance Imaging

OCT: Optimal Cutting Temperature (Cryostat Tissue Embedding Chemical)

LSM: Light Sheet Microscopy

PBS: Phosphate Buffered Saline

IHC: Immunohistochemistry 


\section{Introduction:}

Within biomaterials, the most adapted and common technologies used to follow the growth of an engineered tissue are confocal and multiphoton microscopes[1-3]. With microscopy, cells in the biomaterials are visible by either a genetically transfected fluorescent protein or a chemical probe $[4,5]$. Although these labeling techniques are available, not all cell types possess a transfected fluorescent protein and chemical probes aren't entirely protein specific [4, 6]. For the scientists interested in tracking a specific cell type, protein bound to its membrane or understanding a cells secretome in a biomaterial, these experiments rely on immunolabeling with antibodies. For the moment, visualization of immunolabeled proteins by microscopy is to some degree possible in translucent biomaterials (hyaluronic acid[7], collagen[5] and Matrigel gels[8]) although light refraction or antibody diffusion are limitations[5].

In histology, tissue-sectioning machines cut dense and thick tissues down to $\mu \mathrm{m}$ thicknesses. Accordingly, the histology's thin sections only require the antibody to penetrate a few um; this penetration distance is far less than in well microscopy. Furthermore, histology can outperform traditional in-well microscopy by its versatility. For example, various histology techniques can be applied to a single sample. In histology, the single sample can be cut into hundreds of sections and processed for chemical staining, immunolabeling, in-situ hybridization, laser capture micro-dissection and electron microscopy[9]. These experiments provide the scientist with location-based information on cells, proteins, DNA or RNA for a single sample. In contrast, this multicharacteristics approach is not yet achievable in conventional in-well microscopy.

Histological analysis of cells in biomaterial exists. The content of a well of interest (for example at time point 0 vs. later time points) is transferred (via aspiration or grabbing $[10,11])$ to a mould for flash freezing. In this conventional histology approach we believe important information is lost. For instance in transferring, the cell culture media containing cell-secreted elements are moved away from their source. Because of this, we lose the ability to examine the cell's secretome by histology. Additionally, the mechanical forces of the aspiration modify the cell and biomaterial distribution. Without these mechanical transferring forces, histology could provide information on cell attachment or the extent of the vertical structural support in a $3 \mathrm{D}$ environment. For this 
reason we decided to improve the approach used for histology analysis of cells in biomaterials. We hypothesized that a custom-made well insert could hold the biomaterial/cell mixtures, withstand culturing conditions, permit cell survival, be individually removable, cryosectionable, and permit direct biomaterials and cells processing for histologic experiments. Well inserts are already available for certain cell culture applications[12], but the novelty of our technology is the development of a well insert that can be easily used for cryopreservation of individual samples and their future cryosectioning. We name our technology the 3D-Cryo Well Insert.

The series of experiments we show used the salivary acinar cell line NS-SV$\mathrm{AC}[13,14]$ embedded in various biomaterials. The NS-SV-AC were used since we are currently working on engineering salivary secretory units intended to improve salivary hypofunction[15] patients' quality of life. The characterization of these cells growth in complex soft biomaterials is of importance for salivary tissue engineering research. Other groups have attempted to engineer salivary structures in biomaterials including, hyaluronic acid[7], polyethylene glycol[16], Matrigel[17-19], collagen gels[20], placenta basement membrane extract and fibronectin[21]. To test the applicability of the 3D-Cryo Well Insert, we tested it in four soft biomaterials: Matrigel ${ }^{\circledR}[22]$, GrowDex ${ }^{\circledR}[23]$, Myogel[24], as well as a composite Myogel+GrowDex.

Here we developed a new technology the "3D Cryo Well Inserts" that allows for histologic characterization of cell cultures directly from the well over time. We demonstrated how cell culture histology was significantly simplified; various liquid or gel biomaterials could be easily cryosectioned and cells stained by using either chemical or immuno-labelling methods. 


\section{Materials and Methods}

\subsection{Design and Fabrication of the "3D-Cryo Well Insert"}

When purchased, gelatine capsules (size 000, www.capsuline.com) were composed of a short wide and long thinner fragment held together by friction (Figure 1e). The longer of the two gelatine capsule fragments was placed in the wells of a 48 well plate (3548, Costar or 150678, Nunc) (Figure 1a). The capsules were trimmed to permit the well plate's lid closure (Figure 1b,c). After lid closure test, paraffin pellets (00403, Histowax) were melted in a glass beaker on a hot plate at $60^{\circ} \mathrm{C}$. The appropriately trimmed capsule fragments were removed one by one from the well plate and dipped in liquid paraffin for 2 seconds and placed aside to cool on aluminum foil (Figure 1d). After the first layer, a second layer of paraffin was applied in the same manner (Figure 1e). The coated capsules were then returned to the well plates and exposed to UV light for at least 30 minutes (Figure 1g). Additionally, after the UV exposure, we quality controlled the well inserts' structural integrity and bacterial contamination. For this, the inserts in 48 well plates were incubated at $37^{\circ} \mathrm{C}$ overnight with 500ul of media. The successful quality controlled 3DCryo well inserts were emptied of media and air dried in a biosafety cabinet. For later usage, unused quality controlled well inserts could be stored in sterile conditions.

\subsection{Cells, Biomaterials, and Conditions Tested}

EpiMax (002-010-CL, Wisent) was the cell culture media used to culture the NS-SV-AC. The cells were negative to mycoplasma. To demonstrate the concept that our 3D Cryo Well Insert allowed preservation of the 3D structural relationships between biomaterials and cells, we tested its use in two liquid biomaterials, and three gel like materials. In the liquid conditions we expected the cells to sink to the bottom of the well. For the liquid biomaterials in the 3D-Cryo Well Inserts we placed cells in Myogel (a human leiomyoma-derived matrix suspension in media) and in cell culture media. The preparation of the biomaterial Myogel was described in detail in another publication[24]. The Ethics Committee of Oulu University Hospital approved our use of the myoma tissue obtained from a patient's uterus leiomyoma. In the gelled conditions, we expected the cells to distribute in 3D throughout the entire length/depth of the well insert. These gels 
included Matrigel ${ }^{\circledR}$ (a basement membrane extract from a mouse tumour) and GrowDex ( (a nano-cellulose hydrogel). To add another biomaterial to this more structured group of biomaterials, we created a composite biomaterial by combining Myogel and GrowDex together (Myogel+GrowDex).

Initially, cells and biomaterials were tested at different concentrations (Sup. Tab. 1). Cells were seeded at different densities $50 \times 10^{3}, 150 \times 10^{3}, 250 \times 10^{3}$. Matrigel (354234, Corning) and Mayogel (Lot 270117, Salo Lab) were tested at 0, 0.5, 1.3, 2.0, 2.6, 3, and 4 $\mathrm{mg} / \mathrm{ml}$. GrowDex (UPM) was tested at $0,0.2 \%, 0.5 \%$ and $1 \%$. The results showed optimal conditions and were used in the experiments described below.

Cells were passaged, counted and directly mixed to each biomaterial. The mixing of the cells in the biomaterials occurred at the following temperatures: at room temperature with $0.5 \%$ GrowDex, and at $4{ }^{\circ} \mathrm{C}$ to prevent gelation with the other biomaterials tested. They were: Matrigel at $3 \mathrm{mg} / \mathrm{ml}$, Myogel at $3 \mathrm{mg} / \mathrm{ml}$, and the composite Myogel+GrowDex at $3 \mathrm{mg} / \mathrm{ml}$ and $0.5 \%$. We added to the 3D-Cryo Well Insert, $150 \mu$ of the cell/biomaterial mixture. After this first addition, $50 \mu \mathrm{l}$ of media/biomaterial without cells were added to bring the final volume to $200 \mathrm{ul}$ in the well insert. Every 4 days, a new 50ul of media/biomaterial was added to provide nutrition and hydration to the cells. Each biomaterial had four replicates for $\mathrm{T}=0$ and $\mathrm{T}=14$ days.

\subsection{Cryopreservation and Cryosectioning}

Each 3D-Cryo well insert was processed one at a time. Accordingly, tweezers were used to transfer the 3D-Cryo well insert from its culture plate to liquid nitrogen. Within 20-30s in liquid nitrogen, the inserts were frozen (Figure 2a). In another well plate, we stored the liquid nitrogen frozen 3D-Cryo well insert in a $-80^{\circ} \mathrm{C}$ freezer overnight or further processed them for cutting right away. The further processing involved embedding the 3D-Cryo well insert into OCT (1708801018, Algol) a liquid used to freeze cryosectioning samples. This OCT embedding step resulted in having the 3D-Cryo well insert inside an OCT frozen cylinder. To perform this OCT embedding step we created a mould (W.I Mould) built from a $15 \mathrm{ml}$ conical tube cut at the $12 \mathrm{ml}$ mark (Figure 2c). The embedding went as follows: first we filled the empty W.I Mould to $90 \%$ with $37 \%$ OCT and 
submerged it in liquid nitrogen (OCT should not contact the liquid nitrogen) (Figure 2b). Then once we noticed a thin circular freezing ring of the OCT we removed the W.I Mould from the liquid nitrogen. At this point, we glided the $-20^{\circ} \mathrm{C}$ or $-80^{\circ} \mathrm{C}$ preserved 3D-Cryo well insert into the cold OCT liquid of the W.I Mould (Figure 2c). The W.I Mould containing the 3D-Cryo well insert was placed again into liquid nitrogen for 1$2 \mathrm{~min}$ (Figure 2d) until the OCT changed to white and bubble emission decreased. At that point, we removed the W.I Mould and its contents from the liquid nitrogen. When frost was seen accumulating on the outer plastic of the W.I Mould, the lid could be removed and an OCT cylinder containing the 3D-Cryo well insert could be ejected with slight pressure (Figure 2e). After ejection, the cylinder on its own without the W.I Mould was cooled again in liquid nitrogen until bubble emission had decreased. OCT cylinders were incubated overnight in a $-80^{\circ} \mathrm{C}$ freezer or transferred to the cryotome for sectioning (Figure $2 \mathrm{f}, \mathrm{g}$ ) or to $-20^{\circ} \mathrm{C}$ for long-term storage. Sectioning was performed on a cryotome (2800 E Frigocut, Jung) with the blockhead near $-25^{\circ} \mathrm{C}$ and the chamber near $-30^{\circ} \mathrm{C}$. On histology glass slides (SuperfrostPlus, Fisher) we mounted $20 \mu \mathrm{m}$ sections (Figure 2h). Over the cutting period, the sections mounted on glass slides air dried and were afterwards stored at $-20^{\circ} \mathrm{C}$. This whole procedure is shown in Supplementary Video 1 .

\subsection{Cell/Tissue Fixation and Permeating}

On staining days, we thawed slide from -20 to $37^{\circ} \mathrm{C}$ in an air incubator. Prior to all stains, we used two 10 min incubation to fix and permeate cells. We followed both incubations with water rinses and used chemicals $10 \%$ home-made neutral buffered formalin (F1635-500, Sigma) and 1\% Triton X-100 (T8787-50, Sigma) respectively. We also removed some unnecessary debris resulting from the 3D-Cryo well insert; we used xylene to removed excess paraffin and fine tweezers to remove gelatine strands.

\subsection{Sirius Red Chemical Stain}

Sirius Red and hematoxylin were used as general stains to visualize the biomaterials and cells. First, see fixation and cell permeating steps. From water, slides 
were exposed to $10 \mathrm{~min}$ of Weighert's hematoxylin. Some chemicals in the hematoxylin were: hematoxylin (4305, Merck) and Iron (III)-chloride hexahydrate* (3943, Merck). From the hematoxylin, the slides were individually gently stirred and stored in water. Then, the slides were exposed for at maximum of 3 min to home-made Sirius Red $(0.1 \mathrm{~g}$ of Direct Red 80 (365548-5G, Sigma Aldrich) in $100 \mathrm{ml}$ of saturated picric acid solution). Then the slides were exposed for $5 \mathrm{~min}$ in 5\% acetic acid in water, transferred to $100 \%$ ethanol, completely dehydrated with xylene and mounted with organic media.

* We calculated molar equivalents, anhydrous is recommended in literature[9].

\subsection{IHC: Collagen Panel \& Ki-67}

General: Ki-67, a marker for non-senescent cells [25], was used in our study to demonstrate that the 3D-Cryo well insert did not decrease the rate of cell proliferation. Collagens I-V were also stained to show how the 3D-Cryo well insert can preserve secreted proteins in proximity of their source, the cells. Before staining we performed fixation and cell permeating steps. After the staining, we dehydrated the slides from water to ethanol gradients then xylene and mounted with organic media. We used fresh human myoma tissue samples sections from a previous publication[26, 27] and human brain tissue as some of the immunohistochemical controls (Sup. Fig. 5).

We diluted Ki-67 antibody (Clone MIB-1, 80mg/ml, Dako) at 1:125 in PBS and we processed the slides with an automatic slide stainer (BOND-MAX, Leica). We treated the slides with bond polymer refined detection kit (DS9800, Leica). This involved epitope retrieval in citrate buffer for $20 \mathrm{~min}$, then incubation with the primary antibody for $60 \mathrm{~min}, 30 \mathrm{~min}$ in the post primary, $30 \mathrm{~min}$ in the polymer, $10 \mathrm{~min}$ in the DAB and 5 min in the hematoxylin. Throughout the experiment, the slides were washed with the washing buffer provided by the company.

We diluted Collagen Panel I- $V$ antibody (PA136058, ThermoFisher) in antibody diluent at 1:400 (S2022, Dako) and proceeded to immunostaining using autostainer (E172566, LV-1, Labvision). In our tested conditions, this antibody did not require epitope retrieval. We applied the Col Pan Antibody for $60 \mathrm{~min}$ and rinsed with 1X TBST. We added Dako REAL Peroxidase Blocking Solution $5 \mathrm{~min}$ and rinsed for 5 min with 
water and $1 \mathrm{X}$ TBST. We added Bright Vision poly HRP-Anti-Rabbit IgG (VWRKDPVR500HRP, ImmunoLogic) for $30 \mathrm{~min}$ followed by 1X TBST rinse. We applied the $\mathrm{DAB}+$ chromogen in substrate buffer (K5007, Dako) for 5 min followed by 1X TBST and water rinse. We added Mayers Hematoxylin HTX Plus (01825, Histolab) for 10 min and rinsed with TBST 1X. A blocking step was tested but did not show difference from no blocking.

\subsection{Imaging}

We captured low magnification (2.5X objective) images with an Axio-Imager (Zeiss) using the tiling and stitching function in the Zen software (Zeiss). We captured the higher magnification (20X objective) images using two microscopes: for Sirius Red, Zeiss's Axio-Imager and for Collagen Panel and Ki-67, Leica's DM4000. 


\section{Results}

\subsection{D-Cryo Well Insert Fabrication and Resistance to Cell Culture Conditions}

The uncoated gelatine capsule could not withstand culturing conditions and within a few seconds of exposure to PBS it dissolved (Sup Fig 1a, b). With a single paraffin coating, some capsules still degraded (Sup Fig 1c), but after two layers of coating, the structural integrity was maintained and did not leak during 14 days; at that point the experiment was terminated. During the incubating, the 3D-Cryo well insert fused slightly to the walls of the well plate. Slight twisting facilitated the insert's detachment (Figure 1).

\subsection{Cryosectioning of the Histology Well Insert}

We added test biomaterials to the 3D-Cryo well inserts and flash froze them. As the blade passed through the section, the brittle gelatine component shattered, but we could still distinguish the biomaterial in the well's shape. A standard blade of a cryotome was able to cut the 3D-Cryo well insert (Figure 2). We improved the outcome of the tissue's appearance by embedding the 3D-Cryo well insert within a 37\% OCT cylinder where shattering was diminished

\subsection{Biomaterial Concentration and Cell Density Optimization}

Without biomaterials, the sagittal sections of the well inserts were empty. We wanted them to appear crowded, similar to a tissue, and therefore we tested various biomaterial concentrations (Sup. Tab. 1). Below a concentration, (the minimal biomaterial concentration), the crowdedness of the biomaterial on the section was uneven. For Matrigel and Myogel the minimal concentration was $3 \mathrm{mg} / \mathrm{ml}$, and for GrowDex $0.5 \%$ (Sup. Tab. 1). From a sagittal/coronal perspective of the well insert certain biomaterial characteristics resembled those seen in a bright light microscope's transverse planes (Sup Fig 2).

Similarly, we wanted each section to show a dense cellular distribution, and therefore we tested three seeding densities at the minimal biomaterial concentration (Sup. 
Tab. 1). As we progressed through the section of the liquid biomaterials (media \& Myogel) various sizes of cell patches outlined the base of the well. All seeding densities showed cells in the liquid environments. For the more solid biomaterials (Matrigel, GrowDex, Myogel+GrowDex) we had complete vertical distribution of the cells throughout the sagittal section, and the cell density depended on the seeding density. The $250 \times 10^{3} \mathrm{cells} /$ well $/ 150 \mu 1$ showed the best results.

\subsection{Chemical Staining Using Sirius Red: Cell Clustering and Collagen Production.}

We were able to distinguish single cells at day 0 , and in certain materials, the formation of cell clusters at 14 days. (Figure 3 provides high magnification images and in supplementary figure 3, lower magnification images are presented). In the liquid biomaterials (media, Myogel) the cells pooled at the base of the well and formed clusters at day 0 (Fig. 3a, e), and the same at 14 days (Fig. 3b, f). In the relatively more structured and solid biomaterials (Matrigel, GrowDex, Myogel+GrowDex), the distribution of cells was more even (Fig. 3c, g, i), and at 14 days, we saw clear clusters in Matrigel (Fig 3d). In GrowDex (Fig. 3h) there were no clusters, and only very few were seen in the GrowDex+Myogel mixture (Fig. 3j).

Next we looked for collagen production by the cells using Sirius Red staining. Although this chemical stain is not entirely specific, red/pink color intensity shifts near the cells between days 0 and 14, could represent collagen production. At 14 days, the shades of red near cells had changed in Matrigel, Myogel, Myogel+GrowDex. The area in the biomaterial near the cells was darkened in comparison to the stain at $\mathrm{T}=0$ (Sup. Fig. 4 e \& Fig. 3f, j). We saw also greater amount of pink surrounding the cells at 14 days in cultured in media, compared to day 0. (Fig. 3a vs. 3b). These findings were in contrast to GrowDex alone, where the stain remained relatively similar to day 0. (Fig. $3 \mathrm{~h}$ vs. $3 \mathrm{~g}$ ).

We also analyzed the samples in polarizing light microscopy. With the polarizing light microscope accessories, Sirius red positive collagen fibbers should acquire different colors dependant on the type of collagen. Here we analyzed our samples with this type of microscopy to get a better idea of the type of collagen being produced. Our positive control, a human leiomyoma tissue (Sup. Fig. 4a, b) and the GrowDex nanofibers (Sup. 
Fig. $4 \mathrm{j}, \mathrm{k}$ ) shined under polarizing light. In contrast, $\mathrm{T}=14 \mathrm{~d}$ samples of Myogel shined very weakly (Sup. Fig 4h, i) and in the Matrigel or the cell cluster within (Sup. Fig. 4e, f), and in the media (Sup. Fig. 4c, d) these did not shine at all.

\subsection{IHC with Human Ki-67: Cell Proliferation.}

With hematoxylin we demonstrated that in Matrigel individual cells at $\mathrm{T}=0$ clustered at $\mathrm{T}=14 \mathrm{~d}$. We used a human leiomyoma tissue seeded with cancer cells as a positive and negative control for cell proliferation marker Ki-67. In myoma discs, some cancer cells stained positive while others were negative (Sup. Fig. $5 \mathrm{~g}, \mathrm{~h}$ ). The cells in all biomaterials and in media (Figure 4a, c, e, g, i) expressed Ki-67 at T=0. At T=14, cells in GrowDex showed the most dispersed signal localization (Fig. 4h). The Myogel+GrowDex mixture and media had a more condensed and stronger staining (Fig. 4b, j). In Myogel and Matrigel Ki-67 stained most of the cell nuclei (Fig. 4d, f).

\subsection{IHC Human Collagen Panel Antibody: Collagen Production.}

To further investigate the location of collagen molecules, we used collagen-panel antibodies, a human leiomyoma tissue section as a positive (Sup. Fig. 5c, d), and a human brain (Sup. Fig. 5e, f) and GrowDex as negative controls. In Myogel, cells were attached to the endogenous human collagen fibers of the matrix (Fig. 5e, f), 2), and the Myogel in the Myogel+Growdex mixture endowed the GrowDex (Fig. 5g, h vs. i, j). Consequently, the only condition where human collagen synthesis could have be evaluated is the mouse derived Matrigel, GrowDex or media. In the media, at $\mathrm{T}=0$ collagen near the cells was absent (Fig. 5a), and at $\mathrm{T}=14 \mathrm{~d}$ it was still relatively scarce (Fig. 5b). At both time points, cells in GrowDex, did not produce collagens (Fig. 5g, h). However, cells in Matrigel expressed clearly more collagen in proximity to the cell cluster at $\mathrm{T}=14$ than at $\mathrm{T}=0$ (Fig. 5d, Fig. 5c). In Sup. Fig. 6 we provide lower magnification images of the entire well. 


\section{Discussion}

Other in vivo imaging technologies, such as ultrasound, CT, MRI[2, 3], optical coherence tomography[28, 29] and light sheet microscopy[30, 31] are unfortunately not easily adaptable for cell culture plates. The better-suited confocal and multiphoton microscopes provide sufficient data but it cannot be performed with histology. Histological analysis of the cells and tissues is still the golden standard for e.g. most diseases diagnostics. Therefore, we believed that the histology protocol of liquid or gel cultures of engineered tissues is useful and we developed here the 3D-Cryo well insert method.

Well inserts already exist for cell culture applications. In cell culture well plates, they serve as a support to a membrane for transwell membrane experiments[12]. We considered using these inserts but their permeable base and plastic composition made us re-consider its aptitudes for our desired application. As an alternative to a plastic well insert, medical pills come in different sizes and have been used as temporary holding devices for plastic and resin embedding of tissues for histology applications[32]. In the histology applications, the medical pills were never shown to withstand culturing conditions and their use was never intended for long-term cell culture application. As we have shown, any exposure to water or PBS rapidly degrades the pills (Sup. Fig 1). Consequently for our intended long-term culture application, we apply a hydrophobic paraffin coating to the pills (Figure 1). Although it serves as a protective coating, it decreases the lumen and overall volume of the well. For this reason, with the current coating technique, smaller lumen capsules for 96 well plates aren't recommended. Alternative capsules made from hypromellose[33] or other coating technologies[34] (enteric coating) could decrease degradation rates and prevent the need for coating. Future study could explore these alternative pills for use with the cryosectionable well inserts. The greatest cutting challenge was with the most liquid samples and at the interface between the biomaterial and the capsules. This interface challenge isn't new to histologists as it is also reported between bone and soft tissues (decalcification methods exist to soften the bone[9]). To improve the cutting we recommend to: 1) use the cryotome's motorized option, 2) orient the ice block so that cutting starts on the well inserts opening side first 3) optimize the cryotome chamber temperatures (see Mat \& 
Meth). The best cut size consistency was at $\geq 20$ even though $15 \mu \mathrm{m}$ was possible. To reduce reagent costs and quantities we used 37\% OCT; other OCT concentrations were not tested. With too low biomaterial densities, biomaterial gaps filled with media caused visible larger biomaterial voids in the sagittal/coronal sections. With regard to the cell numbers, 3D cultures in 48-well plates require a lot of cells. For closer proximal cell contact we recommend higher than $250 \times 10^{3}$ cells/well.

The Sirius Red induced a strong red cytoplasmic signal for cells grown on glass (Sup.Fig. 7a) and different shades of red in the tested materials. In normal rat salivary glands, the Sirius Red was reported to make acinar cells stand out[35]. Although collagens I-V aren't expressed in these cells (Sup.Fig. 7b) this strong stain may indicate the presence of certain polysaccharides which can interact with Sirius Red, mentioned in some cases not to be entirely specific to collagens[35-39]. Additionally, both hematoxylin and Ki-67 stained all the glass grown cells (Sup. Fig. 7c). Ki-67 was positive in almost all cells on glass and at $\mathrm{T}=0$. We suspect that the SV-40 transfection could cause the continued Ki-67 expression similar to a study reporting this with JC virus infected cells; a virus with close resemblance to SV-40[40]. In the inert biomaterial GrowDex, the cell number seem to decrease and staining with both hematoxylin (Fig. 3g vs. h) and Ki-67 (Fig. 4g vs. h) was diffuse. This observed diffuse signal could be a result of our not yet optimized growth conditions of the cells in GrowDex in standard culturing conditions. Water evaporation rates[41] or swelling[42] of biomaterials were not considered after preliminary tests but could be good starting point in improving GrowDex experiment outcomes. Interestingly, Myogel's addition to GrowDex made the nuclei appear more defined as compared to the GrowDex alone (Fig. 4h vs. j). In Myogel+GrowDex mixture, the Ki-67 expression was more condensed to the nucleus, but cells didn't divide rapidly. Rapid division led to cell clusters, seen in Matrigel. Without the formation of cell clusters, but expression of Ki-67, we suspect the cell cycle is initiated without leading to proliferation. Consequently, without proliferation in Myogel+GrowDex mixture, the mixture still needs more optimization. In contrast, cells in Matrigel had the most apparent proliferation and cells had clearly defined nuclear Ki67 signal. In Myogel and media, the Ki-67 and nucleus shapes seemed similar to Matrigel. In these three materials, cell survival and proliferation seem to be conducive. 
Polarizing light permits birefringence of collagen fibers on the Sirius Red stained slides. Our control, human leiomyoma tissue was strongly birefringent (Sup. Fig. 4a, b). Birefringence of cellulose has also been demosntarted[39] supporting our observations with GrowDex (Sup. Fig. 4k). With Matrigel and Myogel biomaterials and with the cell clusters grown within Matrigel, we were surprised by the absence of strong birefringence (Sup. Fig. 4f, i). These collagen containing matrices may well be lacking collagen fiber structures required for birefringence[36, 38]. Matrigel and Myogel are mechanically and chemically processed preparations[24, 43]. As for the cell clusters in Matrigel, inadequate alignment of the newly synthesized immature collagen fibers are not causing the positive signal similar to mature collagen fibers.

Azuma characterized the NS-SV-AC cells as epithelial acinar cells from the salivary gland[14]. Salivary epithelial cells produce collagen type IV[7, 16]. Since in vivo, type IV collagen locates mainly the basement membrane structures[44], it suggests that the collagen deposition by these cells grown in Matrigel (Fig 5d) is most likely type IV . However, further analyses should be done in order to evaluate the specific type of collagen produced by these cells in Matrigel. In type IV collagen containing Matrigel, we did not expect the cells to produce more collagen, but it may be possible that the cells prefer their own matrix, or the tumorigenic properties of the Matrigel guides the cells to a cancerous phenotype where excessive collagen production can occur in the microenvironment[45-47]. In Myogel, the cells attached to the collagen positive sunken strands (Fig 5e, f). The endogenous human collagen found by the antibody in myogel prevented us from differentiating new collagen production. Similarly, endogenous collagen in Myogel+GrowDex caused the same detection limitation. Therefore, in order to specifically detect newly synthesized collagens, antibodies detecting propetides of the collagen molecules should be used. However, in both Myogel and in combination with GrowDex Sirius Red stained darker red in proximity to the cells, suggesting some modification or synthesis of collagen (Fig 3f, j). In the GrowDex, cell amount and survival optimization might lead to collagen synthesis, but in our tested conditions it was absent (Fig 5h). In the media also the collagen expression was not highly visible (Fig 5b). The paraffin base layer of the capsule does not permit cell attachment, which may be a 
possible requirement for collagen production. Other more complex biomaterials may be needed for more enhanced collagen and other extracellular structures production [48-50]

Currently many challenges exist for in vitro $3 \mathrm{D}$ cell culture characterization. This is especially true for immunolabeling of cells in complex or liquid biomaterials. The well insert technology developed here facilitates the histology characterization of the cells embedded in biomaterials. In this method, using the 3D-Cryo well insert, we were able to monitor the growth of epithelial cells over the course of 14 days in different liquid and gel biomaterials. We were able to analyze the cell and biomaterial configuration and distribution, as well as to apply immunohistochemical staining. This inexpensive well insert technology is suitable for various histology applications for the characterization of $3 \mathrm{D}$ cultures. We encourage also scientists to apply this method for 3D bioprint to characterize their 3D printed structures by immunolabeling. 


\section{Acknowledgement}

We thank Canadian funding agencies MITACS (Globablink) and FRSQ (Doctoral Training) for their research funds for graduate students. We also thank Lauri Paasonen and UPM Biofore Company for their collaboration with their GrowDex product and funds placed into this study. We also thank, the Department of Pathology (Helsinki University), especially Leena Saikko for her instructions and insight on using certain histology equipment. We also thank, Professors Faleh Tamimi (McGill Dentistry) and Matt Harrington (McGill Chemistry) for lending their microscopes for image acquisition.

\section{Conflict of Interest}

UPM Biofore Company provided GrowDex biomaterial free of charge and supplied funds for the purchase of certain histologic reagents. The Salo lab has produced and developed Myogel, provided lab equipment and certain histology reagents. 


\section{References}

[1] B. W. Graf, S. A. Boppart, in Live Cell Imaging: Methods and Protocols, 591 (D. B. Papkovsky), Humana Press, Totowa, NJ 2010, 211

[2] A. M. Leferink, C. A. v. Blitterswijk, L. Moroni, Tissue Engineering Part B: Reviews 2016, 22, 265.

[3] S. Y. Nam, L. M. Ricles, L. J. Suggs, S. Y. Emelianov, Tissue Engineering Part B: Reviews 2015, 21, 88.

[4] F. Progatzky, M. J. Dallman, C. Lo Celso, Interface focus 2013, 3, 1.

[5] V. V. Artym, K. Matsumoto, Current Protocols in Cell Biology 2010, 48, 10.18.1.

[6] A. Gautier, A. G. Tebo, BioEssays 2018, 40, 1.

[7] T. Ozdemir, E. W. Fowler, S. Liu, D. A. Harrington, R. L. Witt, M. C. Farach-Carson,

S. Pradhan-Bhatt, X. Jia, ACS Biomaterials Science \& Engineering 2016, 2, 2217.

[8] S. Degese, G. Benton, Immunofluorescence of Oragniods Embedded in Basement Membrane Matrix, Trevigen, Online 2017.

[9] S. K. Suvarna, C. Layton, J. D. Bancroft, Bancroft's Theory and Practice of

Histological Techniques, Elsevier, London 2019.

[10] C. C. Yang, L. Jenkins, K. J. L. Burg, Journal of Histotechnology 2007, 30, 185.

[11] J.-L. Ruan, N. L. Tulloch, V. Muskheli, E. E. Genova, P. D. Mariner, K. S. Anseth, C.

E. Murry, Tissue Engineering Part C: Methods 2013, 19, 794.

[12] J. Marshall, in Cell Migration: Developmental Methods and Protocols, (C. M. Wells, M. Parsons), Humana Press, Totowa, NJ 2011, 8

[13] M. Azuma, M. Sato, Histology and histopathology 1994, 9, 781.

[14] M. Azuma, T. Tamatani, Y. Kasai, M. Sato, Laboratory investigation; a journal of technical methods and pathology 1993, 69, 24.

[15] J. Miranda-Rius, L. Brunet-Llobet, E. Lahor-Soler, M. Farré, International Journal of Medical Sciences 2015, 12, 811.

[16] A. D. Shubin, T. J. Felong, B. E. Schutrum, D. S. L. Joe, C. E. Ovitt, D. S. W. Benoit, Acta Biomaterialia 2017, 50, 437.

[17] 0. M. Maria, A. Zeitouni, O. Gologan, S. D. Tran, Tissue engineering. Part A 2011, $17,1229$.

[18] V. Szlávik, B. Szabó, T. Vicsek, J. Barabás, S. Bogdán, V. Gresz, G. Varga, B.

O'Connell, J. Vág, Tissue Engineering Part A 2008, 14, 1915.

[19] A. Joraku, C. A. Sullivan, J. Yoo, A. Atala, Differentiation 2007, 75, 318.

[20] A. P. Burford-Mason, I. Dardick, A. Mackay, The Laryngoscope 1994, 104, 335.

[21] O. M. Maria, Y. Liu, M. El-Hakim, A. Zeitouni, S. D. Tran, Journal of Tissue

Engineering and Regenerative Medicine 2017, 11, 2643.

[22] G. Benton, I. Arnaoutova, J. George, H. K. Kleinman, J. Koblinski, Advanced Drug

Delivery Reviews 2014, 79-80, 3.

[23] GrowDex- The Natural Solution for Cell Culture, UPM Biofore Company, Online 2019. 
[24] T. Salo, M. Sutinen, E. Hoque Apu, E. Sundquist, N. K. Cervigne, C. E. de Oliveira, S. U. Akram, S. Ohlmeier, F. Suomi, L. Eklund, P. Juusela, P. Åström, C. C. Bitu, M. Santala, K. Savolainen, J. Korvala, A. F. Paes Leme, R. D. Coletta, BMC Cancer 2015, $15,981$.

[25] T. Scholzen, J. Gerdes, Journal of Cellular Physiology 2000, 182, 311.

[26] A. Al-Samadi, S. A. Awad, K. Tuomainen, Y. Zhao, A. Salem, M. Parikka, T. Salo, Oncotarget 2017, 8, 60123.

[27] S. Nurmenniemi, T. Sinikumpu, I. Alahuhta, S. Salo, M. Sutinen, M. Santala, J. Risteli, P. Nyberg, T. Salo, The American Journal of Pathology 2009, 175, 1281. [28] Y. Huang, S. Wang, Q. Guo, S. Kessel, I. Rubinoff, L. L.-Y. Chan, P. Li, Y. Liu, J. Qiu, C. Zhou, Cancer Research 2017, 77, 6011.

[29] Y. Jung, O. J. Klein, H. Wang, C. L. Evans, Scientific Reports 2016, 6, 1-11. [30] K. Chatterjee, F. W. Pratiwi, F. C. M. Wu, P. Chen, B.-C. Chen, Applied Spectroscopy 2018, 72, 1137.

[31] Z. Elisa, B. Toon, S. C. De Smedt, R. Katrien, N. Kristiaan, B. Kevin, Microscopy Research and Technique 2018, 81, 941.

[32] J. W. Stirling, A. E. Woods, in Bancroft's Theory and Practice of Histological Techniques, (S. K. Suvarna, C. Layton, J. D. Bancroft), Elsevier 2019, 8 [33] S. Missaghi, R. Fassihi, Drug development and industrial pharmacy 2006, 32, 829.

[34] G. Cole, J. Hogan, M. Aulton, Pharmaceutical Coating Technology, Taylor \& Francis, London 1995.

[35] T. W. Weatherford, The Alabama journal of medical sciences 1972, 9, 383. [36] J. A. Kiernan, Histological and Histochemical Methods : Theory and Practice, Scion, Bloxham, United Kindom 2008.

[37] L. F. Nielsen, D. Moe, S. Kirkeby, C. Garbarsch, Biotechnic \& histochemistry: official publication of the Biological Stain Commission 1998, 73, 71.

[38] L. C. Junqueira, W. Cossermelli, R. Brentani, Archivum histologicum Japonicum = Nihon soshikigaku kiroku 1978, 41, 267.

[39] R. L. Delellis, M. C. Bowling, Human Pathology 1970, 1, 655.

[40] A. Ariza, J. L. Mate, M. Isamat, A. Calatrava, A. Fernandez-Vasalo, J. J. Navas-

Palacios, Journal of neuropathology and experimental neurology 1998, 57, 226.

[41] A. Skogberg, A.-J. Mäki, M. Mettänen, P. Lahtinen, P. Kallio, Biomacromolecules 2017, 18, 3936.

[42] R. Kummala, W. Xu, C. Xu, M. Toivakka, Cellulose 2018, 25, 4969.

[43] M. C. Kibbey, Journal of Tissue Culture Methods 1994, 16, 227.

[44] Y. Kadoya, S. Yamashina, Anatomical Science International 2005, 80, 71.

[45] J. Caselitz, P. Schmitt, G. Seifert, J. Wustrow, D. Schuppan, Pathology - Research and Practice 1988, 183, 386.

[46] H. Jaganathan, J. Gage, F. Leonard, S. Srinivasan, G. R. Souza, B. Dave, B. Godin, Scientific Reports 2014, 4, 1.

[47] H. Y. Tanaka, M. R. Kano, Cancer science 2018, 109, 2085.

[48] C. Chen, F. Loe, A. Blocki, Y. Peng, M. Raghunath, Advanced Drug Delivery Reviews 2011, 63, 277.

[49] P. Benny, C. Badowski, E. B. Lane, M. Raghunath, Tissue engineering. Part A 2015, 21, 183. 
[50] A. Sorushanova, L. M. Delgado, Z. Wu, N. Shologu, A. Kshirsagar, R. Raghunath, A. M. Mullen, Y. Bayon, A. Pandit, M. Raghunath, D. I. Zeugolis, Advanced Materials 2019, 31, 1 . 


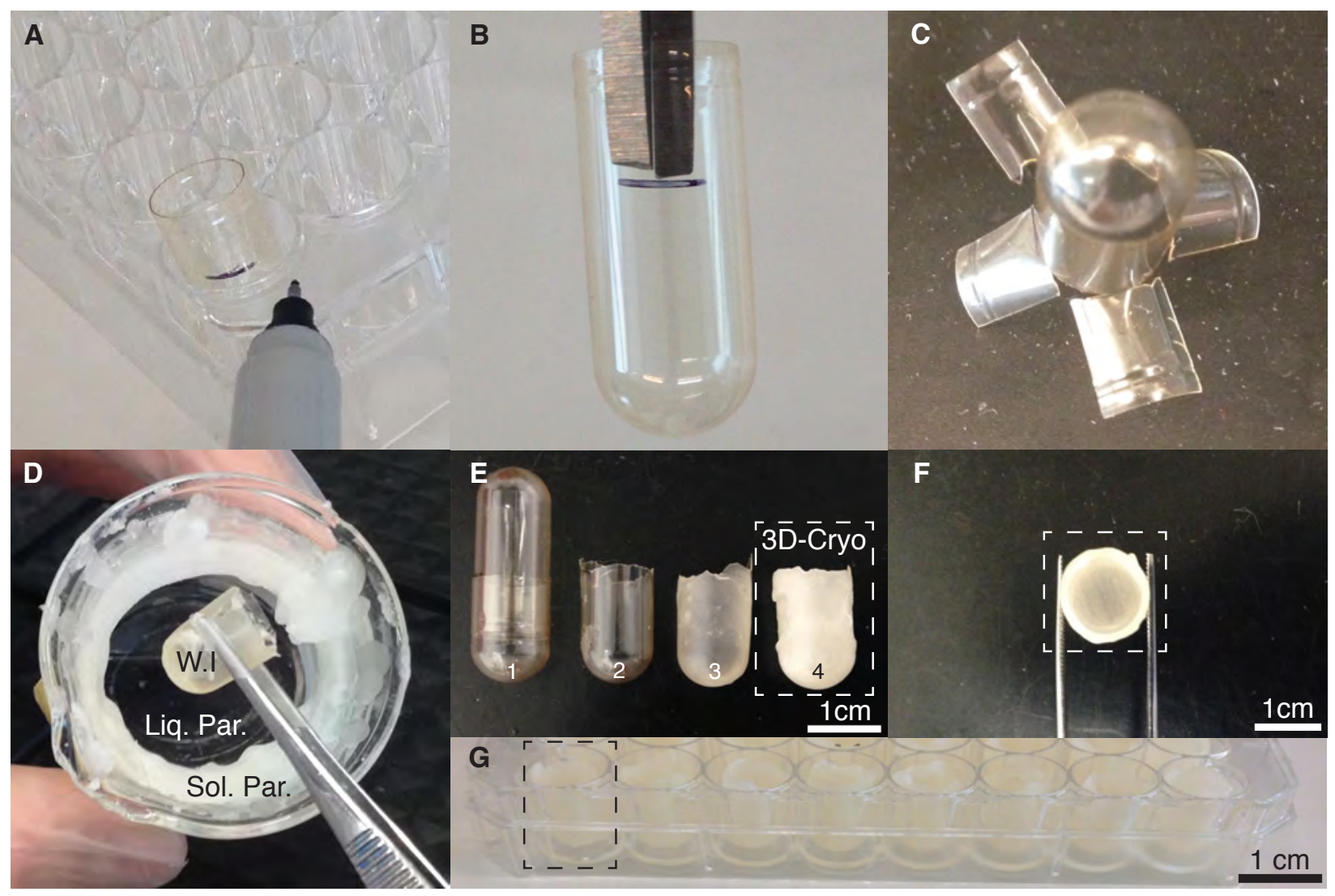

Figure 1. Steps Involved in the Production of the 3D-Cryo Well Insert (W.I). a) Matching the well insert height. b) Cutting to mark with scissors. c) Flaps created from the cut. d) Coating steps in the liquid paraffin (Lid. Par.). On the edges of the beaker solid paraffin (Sol. Par.) is present. e) Appearance of capsules from start to finish. From Left, 1) whole pill, 2) pill cut to size and no coating, 3) pill one coating, 4) pill two coatings or 3D-Cryo Well Insert (Dashed Box), f) Coronal view of the 3D-Cryo capsule (Dashed box), g) Clipping of an image showing a section of a 48 well plate loaded with the well inserts ready for UV (Dashed Box is one 3D-Cryo Well Insert). 


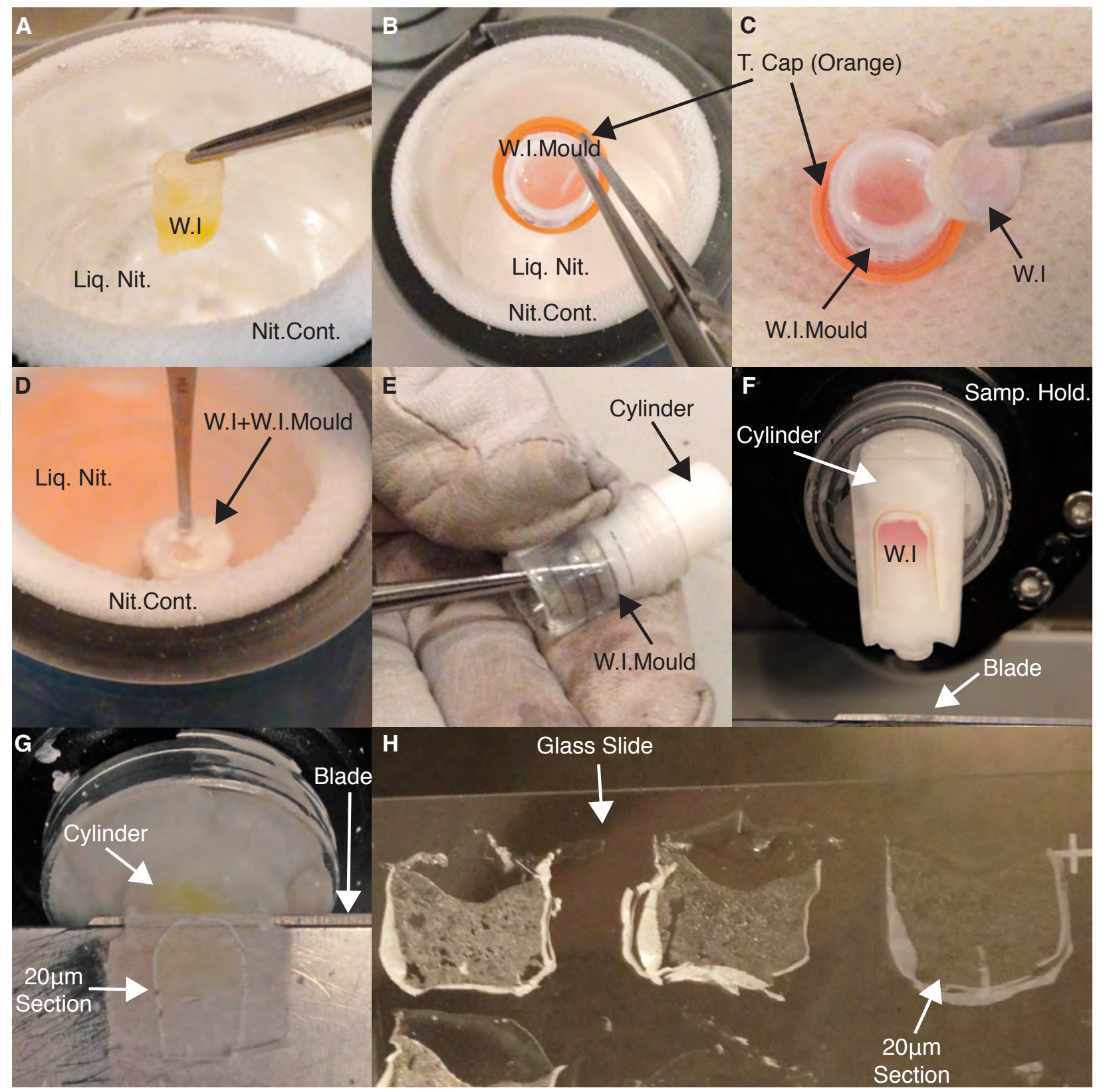

Figure 2. Steps Involved in the Cryosectionning of 3D-Cryo Well Insert. a) Flash freezing well insert (W.I) in liquid nitrogen (Liq. Nit.) contained in a container (Nit. Cont.). b) Flash freezing of mould (W.I Mould) with $15 \mathrm{ml}$ tube cap (T. Cap) in orange filled with $37 \%$ OCT until white layers appears on the perimeter. c) Insertion of frozen well insert into half-frozen W.I. Mould . d) Freezing with liquid nitrogen well insert in mould. e) Ejection of frozen OCT cylinder containing the well insert from mould. f) Ice block half cut with proper directional mounting of ice block on sample holder (Samp. Hold.). We can see the well insert embedded in the OCT cylinder. g) 20 $\mu \mathrm{m}$ section of well insert cylinder still in cryotome chamber. h) Unstained $20 \mu \mathrm{m}$ section of OCT cylinder with well insert mounted on glass slide. W.I has yellow or pink food colouring to help visualize biomaterial levels. 


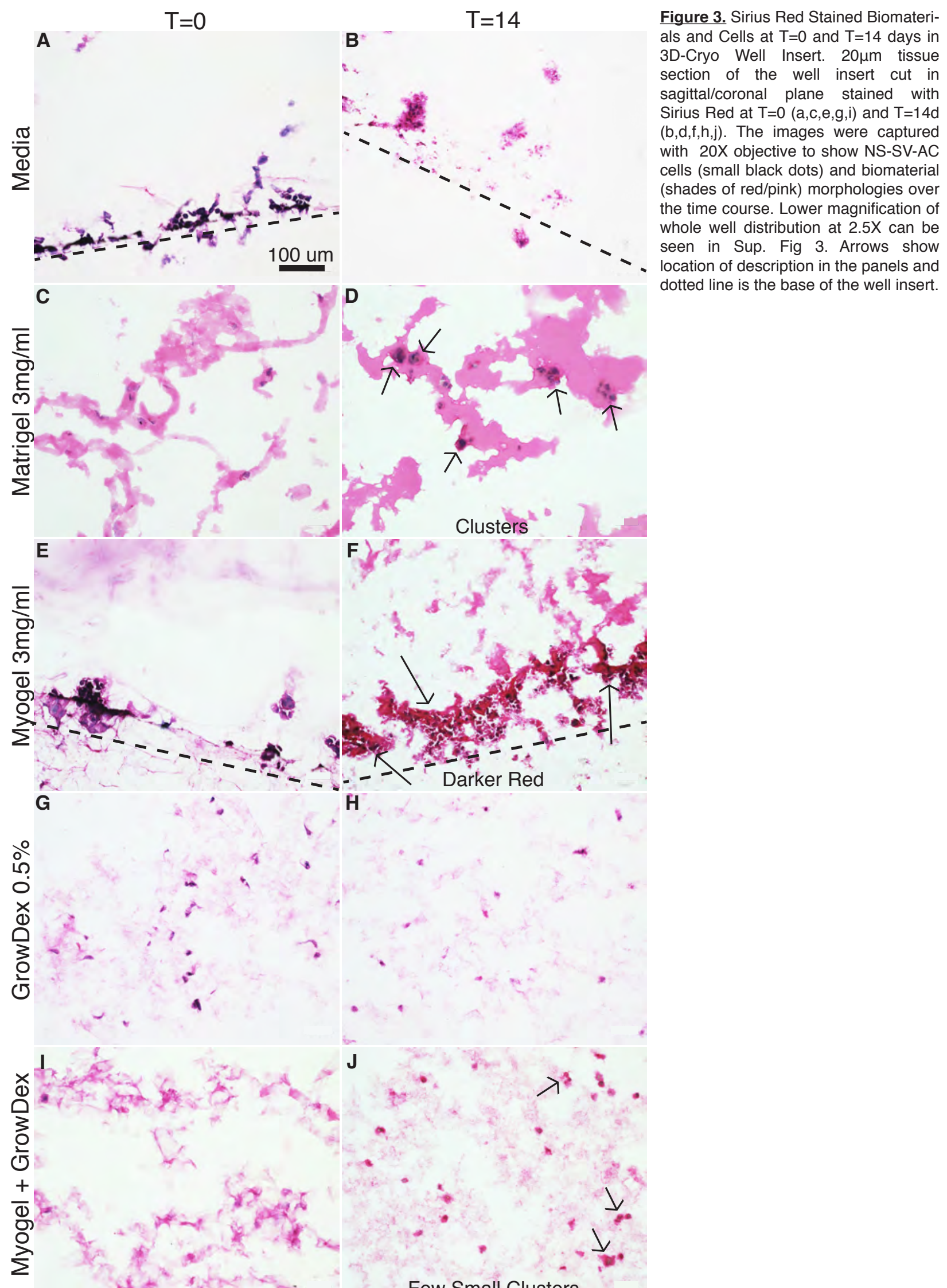

Few Small Clusters 


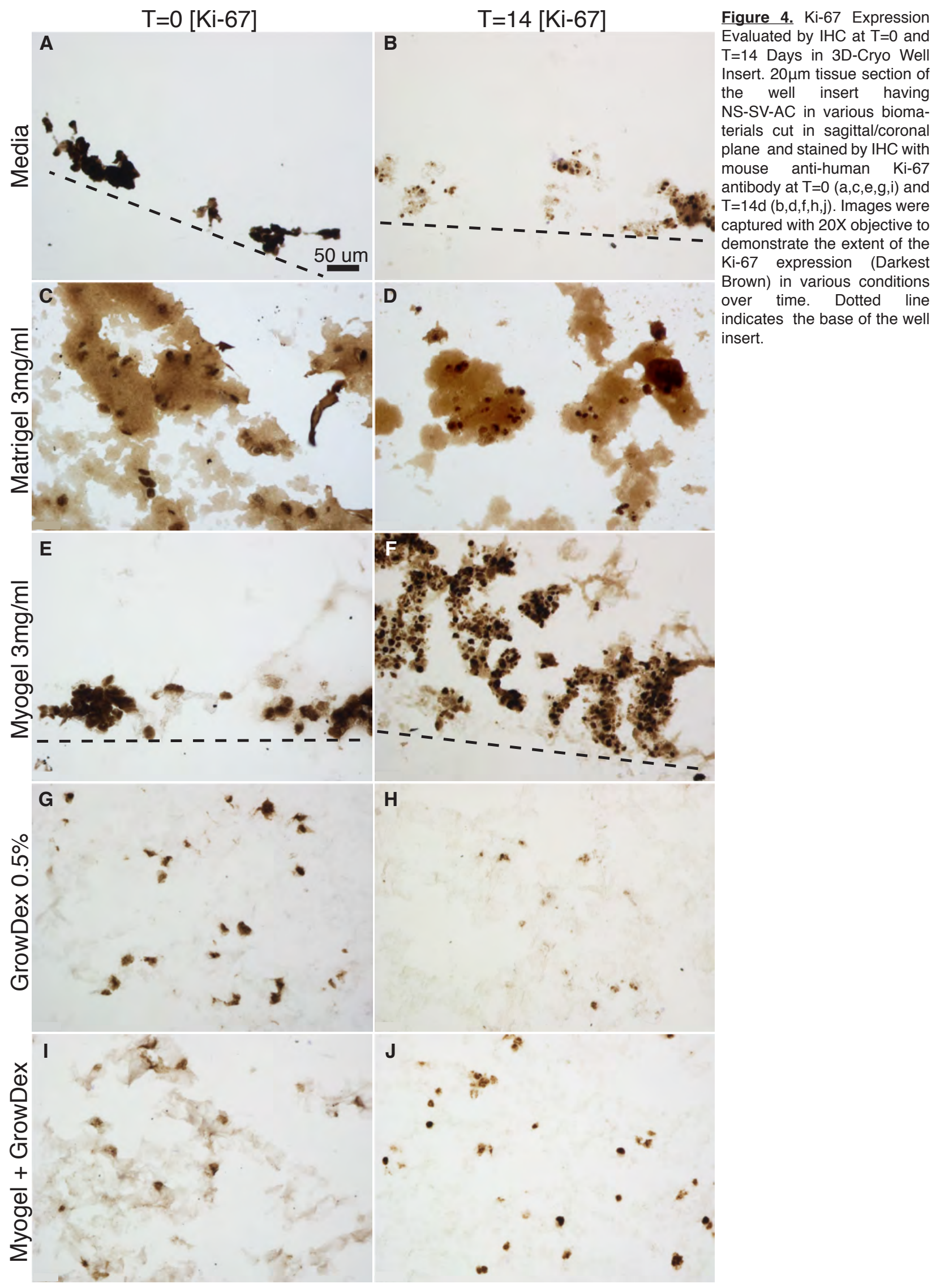




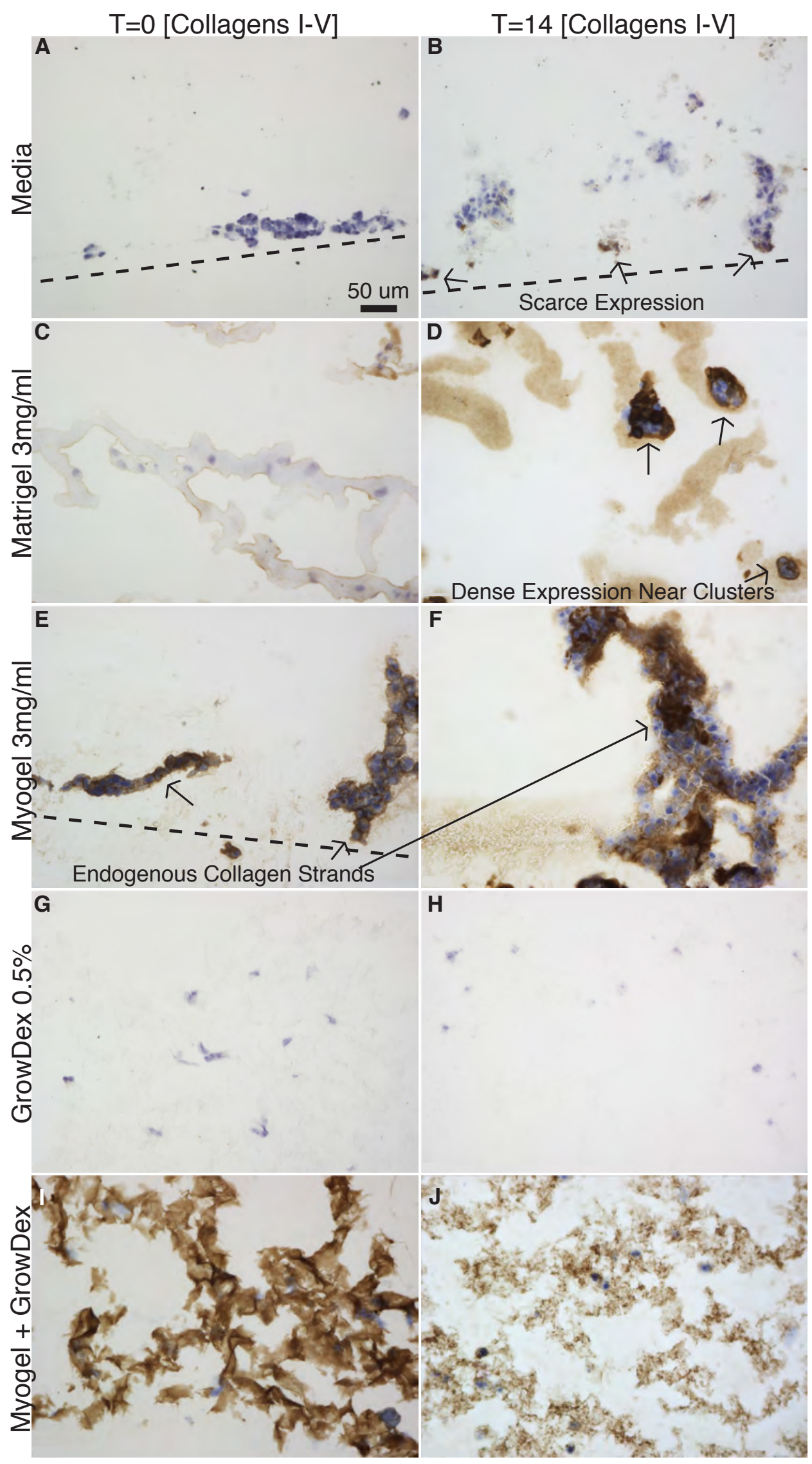

Figure 5. Collagen I-V Expression Evaluated by $\mathrm{IHC}$ at $\mathrm{T}=0$ and $\mathrm{T}=14$ Days in 3D-Cryo Well Insert. 20 $\mu \mathrm{m}$ tissue section of the well insert seeded with NS-SV-AC in various biomaterials cut in sagittal/coronal plane and stained by IHC with rabbit anti-human collagen panel antibody at $\mathrm{T}=0$ (a,c,e,g,i) and $\mathrm{T}=14 \mathrm{~d}(\mathrm{c}, \mathrm{d}, \mathrm{f}, \mathrm{h}, \mathrm{j})$. The images were captured with $20 \mathrm{X}$ objective to show the extent of the cell's collagen I-V expression (brown) over the time with location of nuclei (blue). Lower magnification at $2.5 \mathrm{X}$ can be seen in Sup. Fig 6. Arrows show location of description in the panels. Dotted line indicates the base of the well insert. 

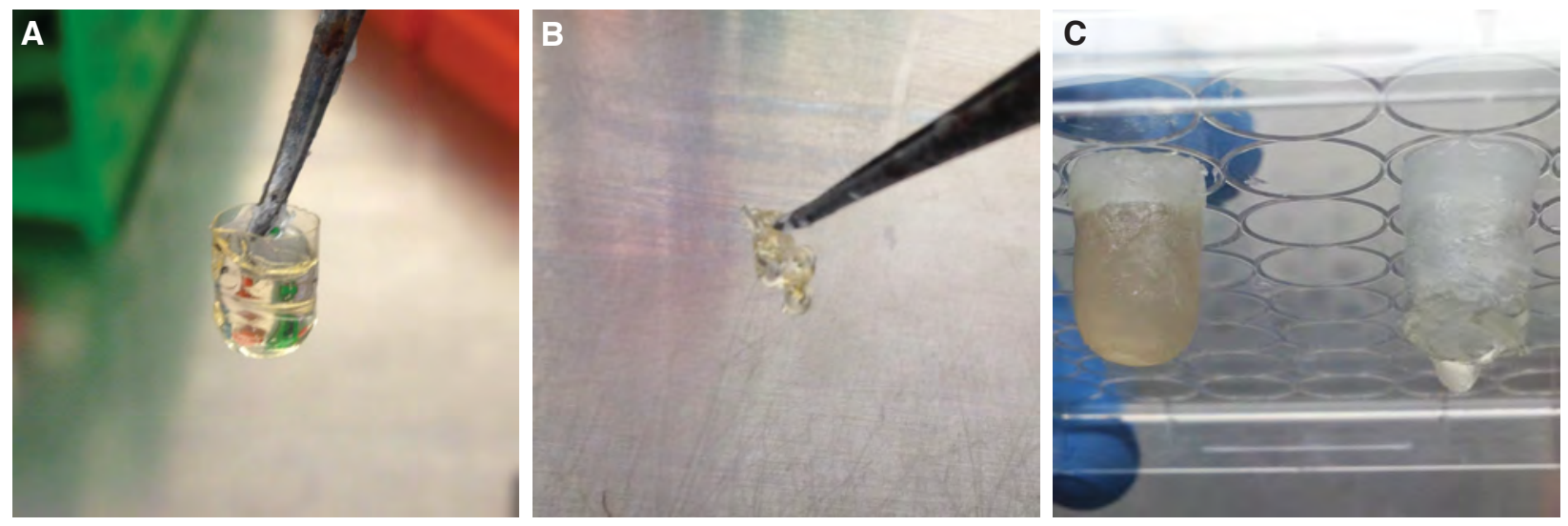

Supplementary Figure 1. Inadequate well inserts made from uncoated gelatine capsules or single coated capsules. These trial well inserts were never used in experiments containing cells and biomaterials, they were only used when testing coating requirements for long-term incubations. a) Uncoated gelatine capsule with PBS T=0. b) Uncoated capsule Time=seconds. c) Two gelatine capsule with one coating of paraffin; with one coating, about $50 \%$ fail to retain liquid. 


\section{Inverted Bright Light Microscope

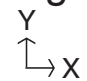

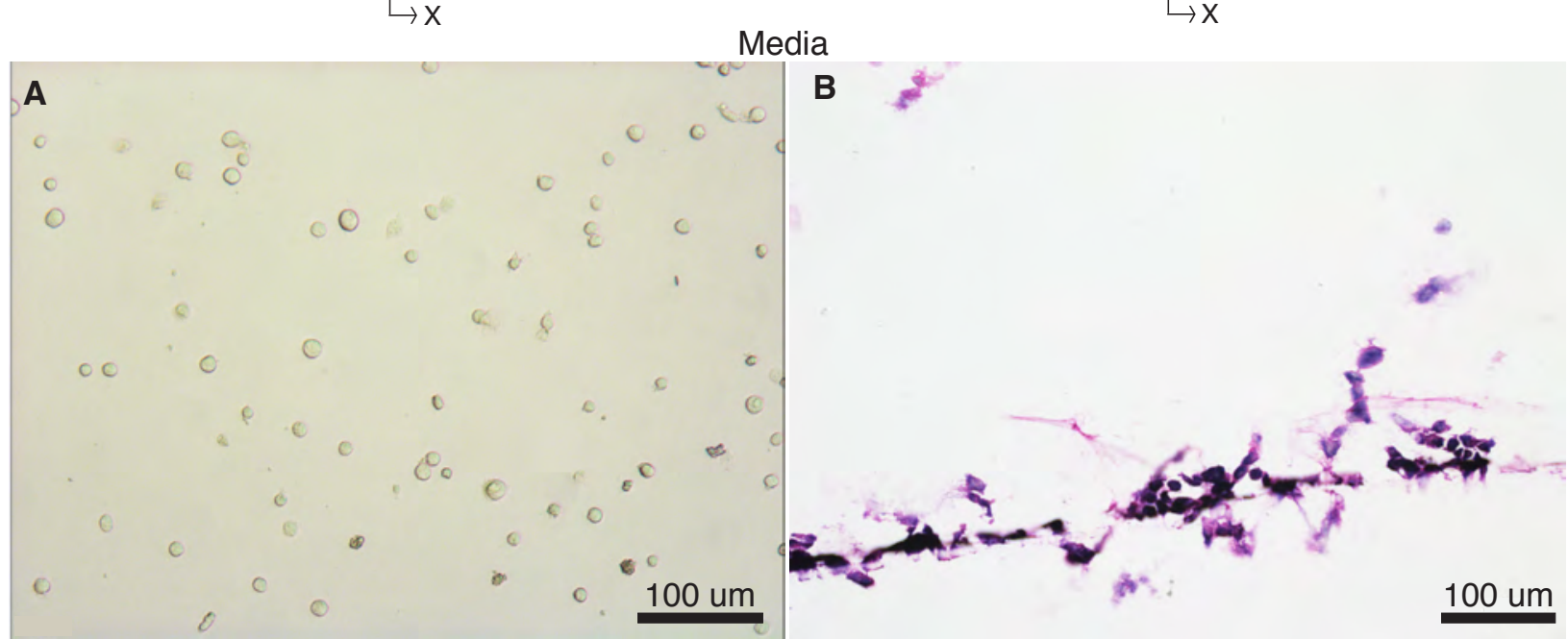

GrowDex
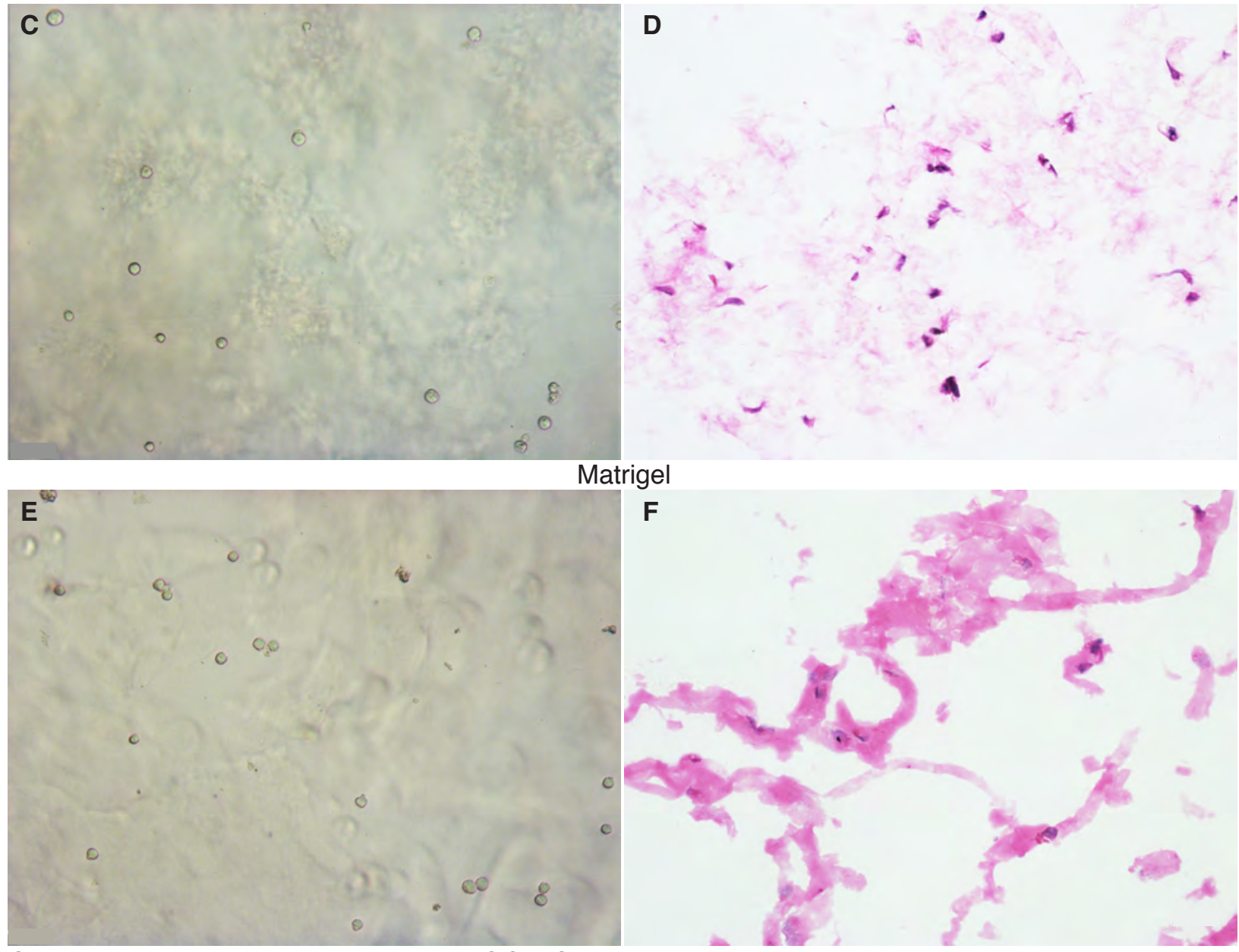

Supplementary Figure 2. Bright light images of NS-SV-AC in normal wells in various growth conditions at $\mathrm{T}=0$. The appearance of the biomaterials on this inverted microscope in the transverse plane $(a, c, e)$ resembles what the biomaterial looks like in the sagittal/coronal plane of the section of the well insert (b,d,f). In a,b,c,e, focus is on the bottom of the dish while in d,f its above. $a, b)$ Media, notice no biomaterial. c,d) GrowDex, notice the granular appearance of the biomaterial. e,f) Matrigel, notice the sheet like appearance of the biomaterial. 


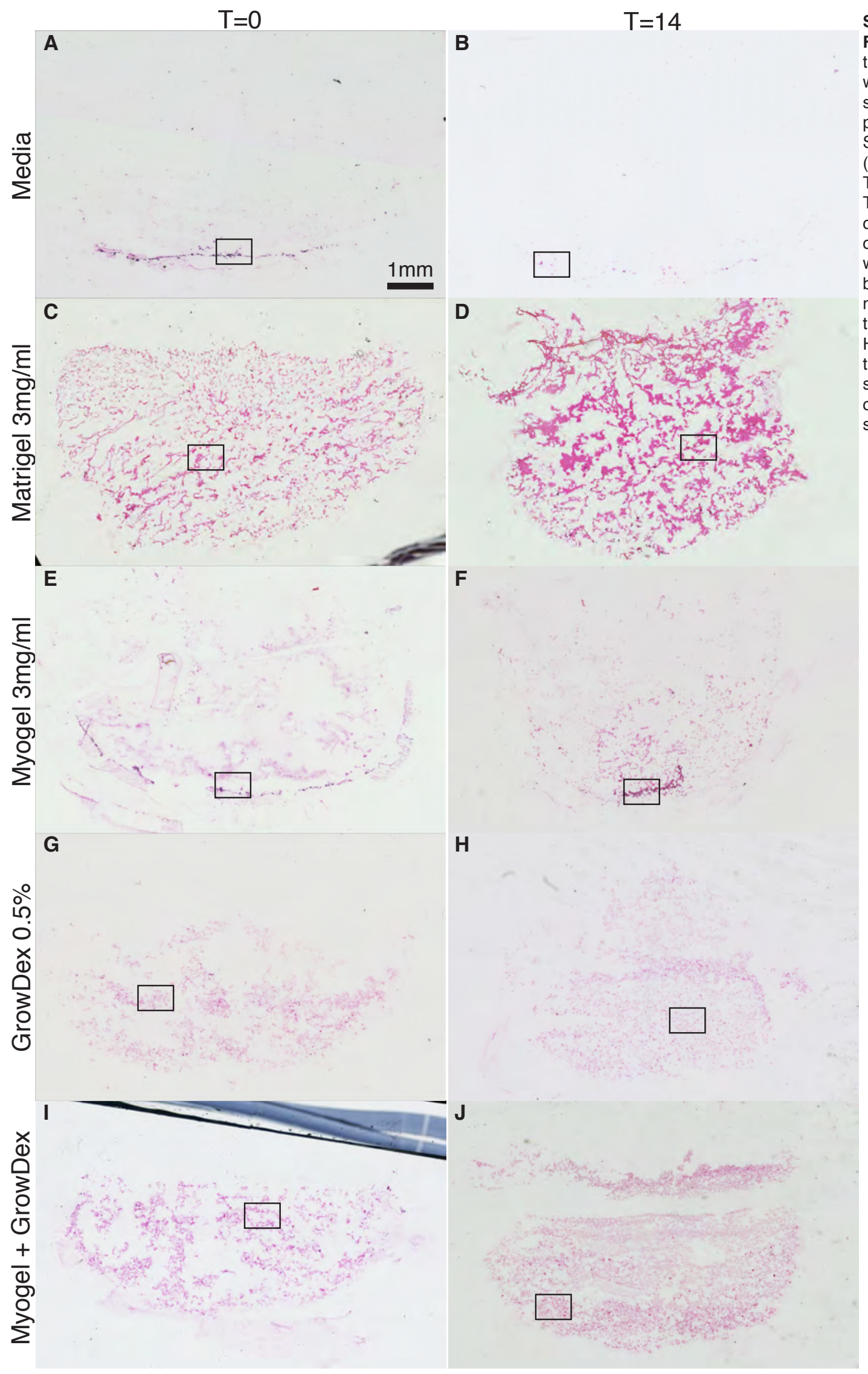

upplementary Figure 3. 20um tissue section of the well insert cut in sagittal/coronal plane stained with Sirius Red at $\mathrm{T}=0$ $(\mathrm{a}, \mathrm{c}, \mathrm{e}, \mathrm{g}, \mathrm{i})$ and $T=14 d \quad(b, d, f, h, j)$. The images were captured with $2.5 \mathrm{X}$ objective to show whole well cell and b i o m a t e ri a I morphologies over the time course. Higher magnification of the black square using $20 \mathrm{X}$ objective can be seen in Figure 3. 
$\mathrm{T}=14$ Days [Sirius Red]
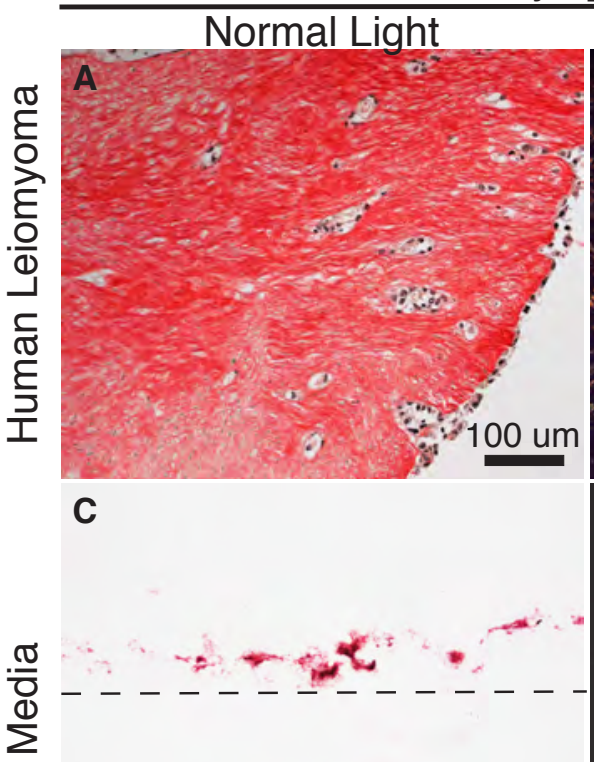

\section{E}

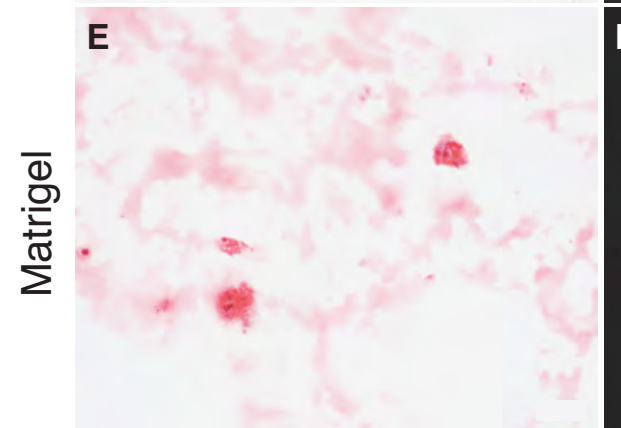

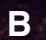
Polarized Light

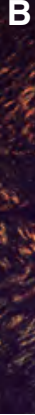

D

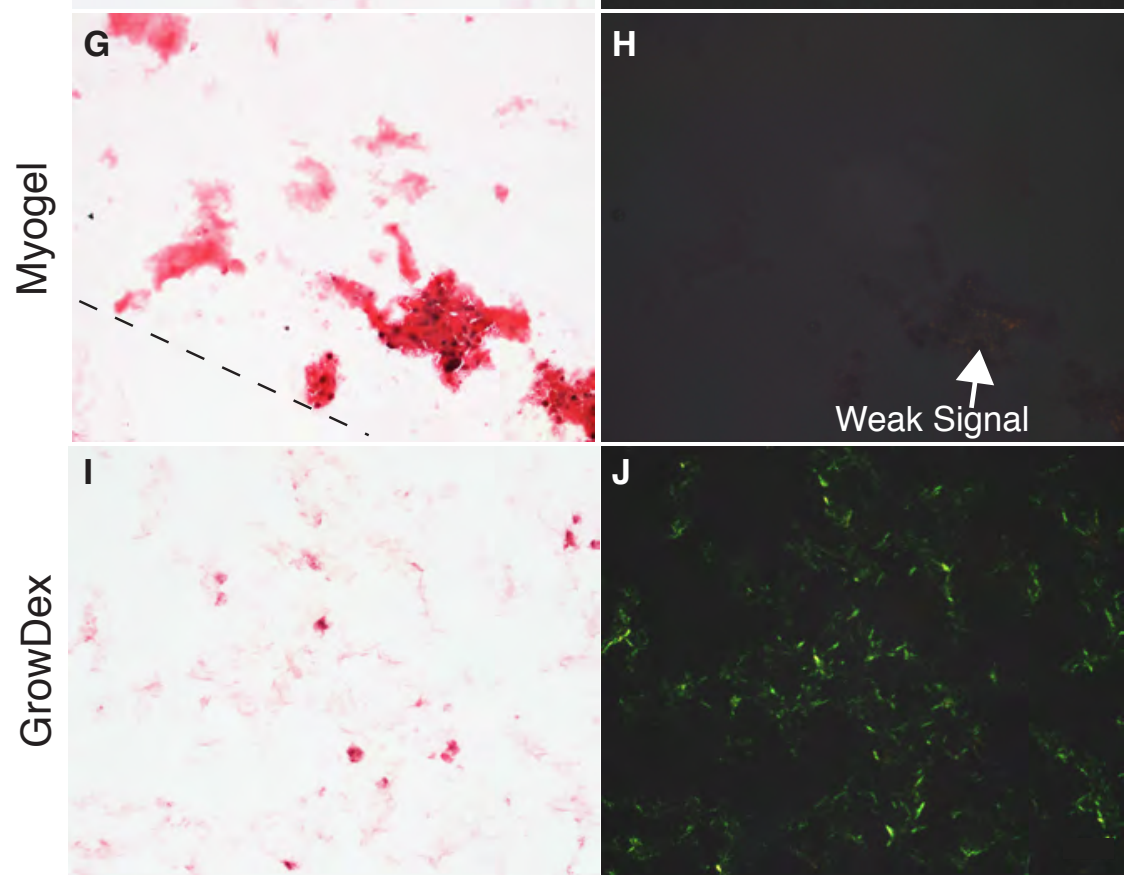

Supplementary Figure 4. Sirius Red chemical stain analyzing section in bright light and in polarizing light. a, b) + Control, human leiomayoma, strong signal in bright and polarizing light. In experimental conditions $\mathrm{c}-\mathrm{k}$, sagittal sections of NS-SV-AC cells in biomaterials at 14 days are shown. c,d) Media, few cells in bright light and no evident signal in polarizing light. e,f) Matrigel, in bright light, clusters of cells differentially stained from background Matrigel but no obvious signal in polarizing light. $h, i)$ Myogel, darker red signal near cells as compared to Mayogel without cells, weak signal in polarizing light near cell clusters in biomaterial. j,k) GrowDex, in bright light, darker red signal in proximity to cells as compared to GrowDex background. In polarizing light strong emission from GrowDex nanocellulose fibres but no obvious from near cells. Dotted line indicates the base of the well insert. 


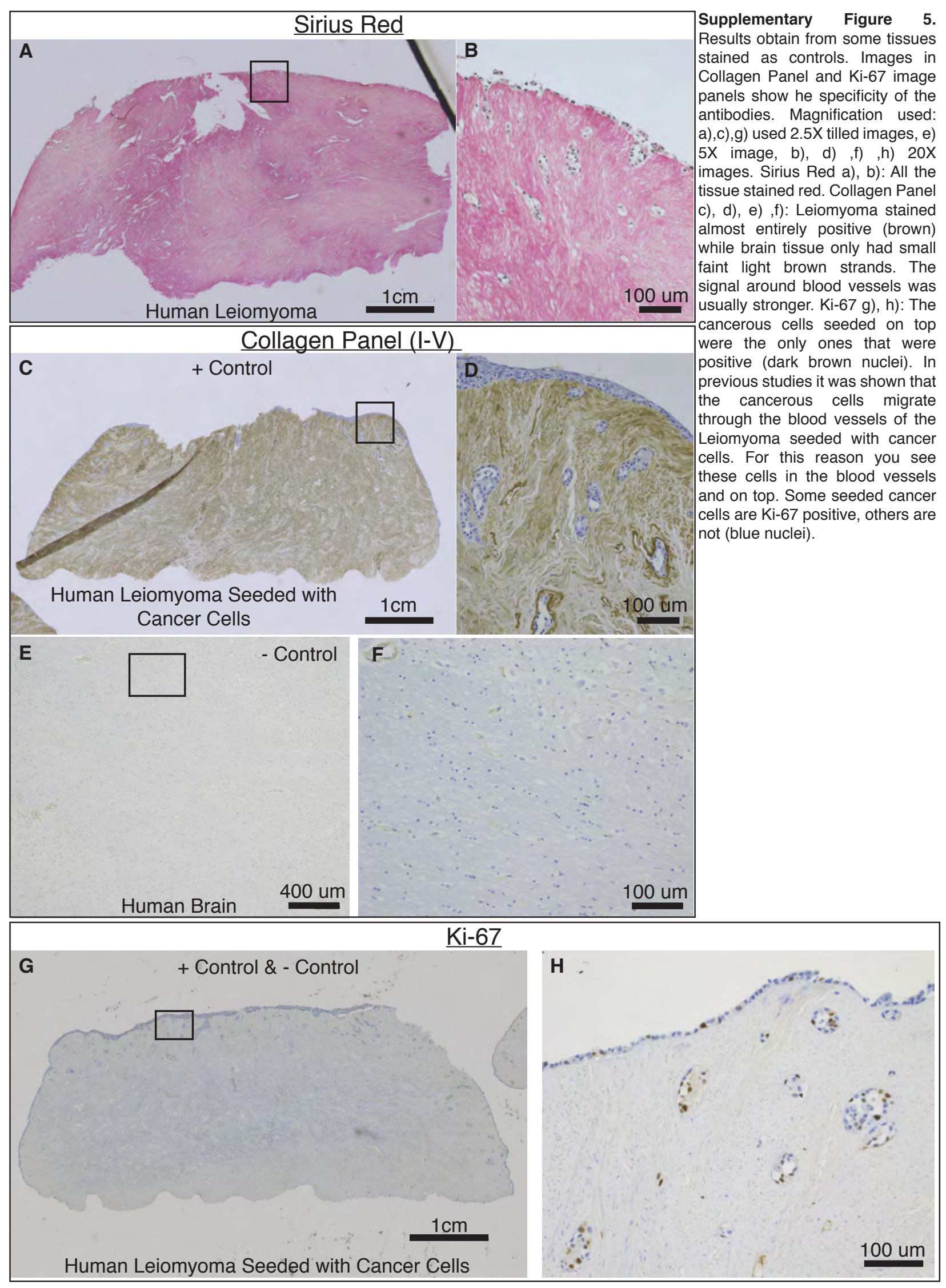




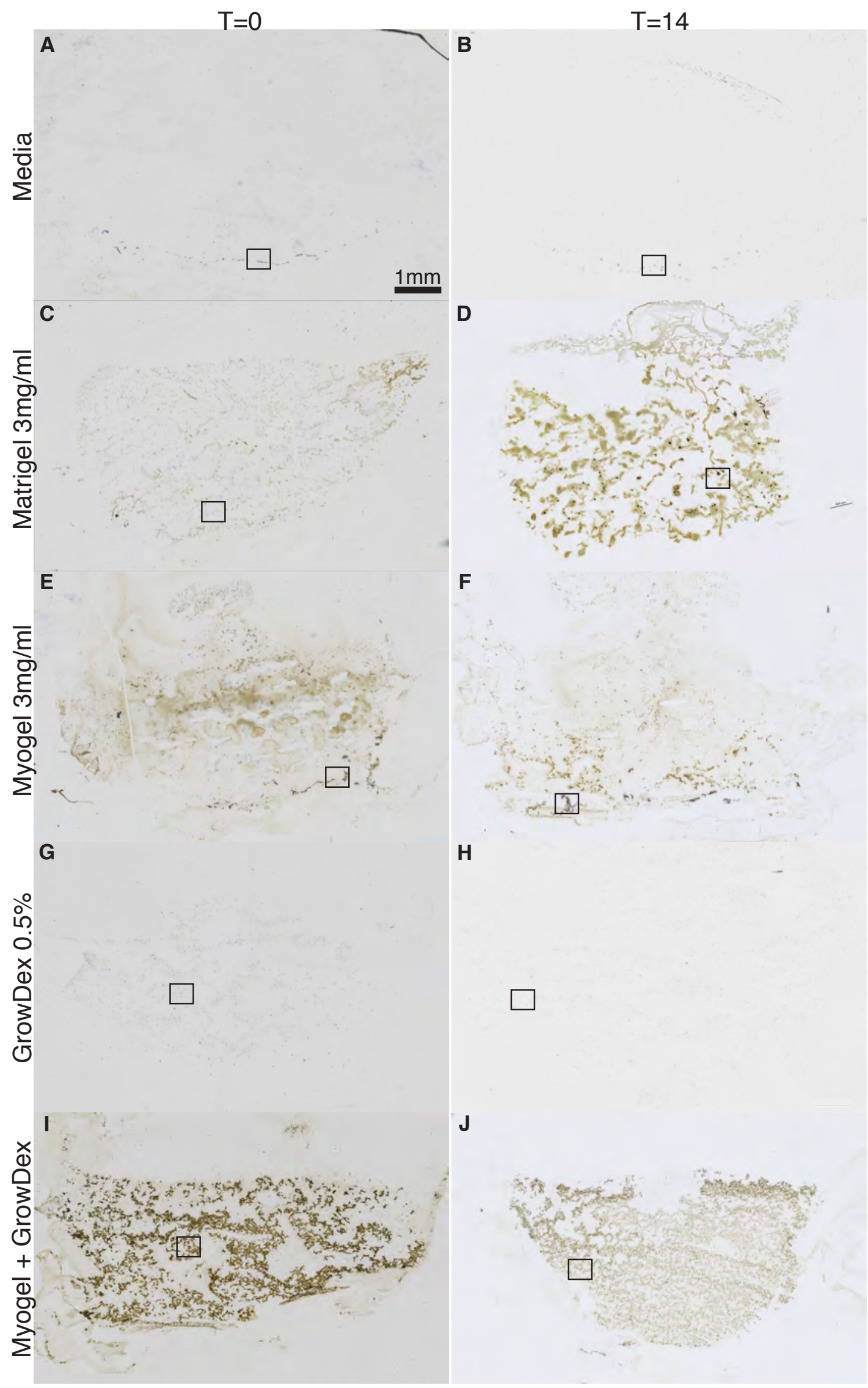




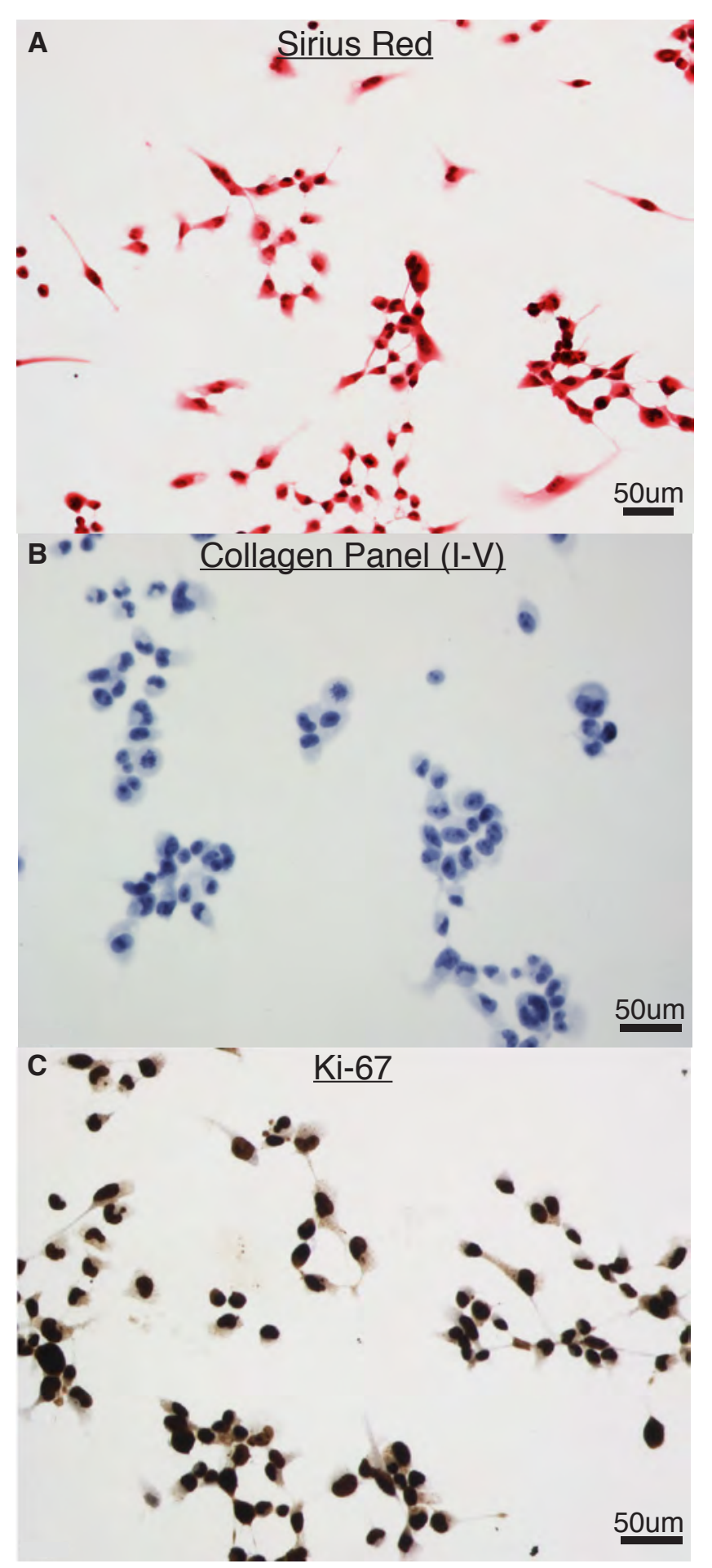

Supplementary Figure 7. NS-SV-AC characterization in 2D culture. The cells were grown on glass for 4-8 days and fixed in $10 \%$ Neutral Buffered Saline (NBF). Proceeded to staining with the same method described in the paper. Images were captued with 20X objective. a) Sirius Red chemical stain showing strong cytoplasmic signal. b) Collagen panel IHC showing no collagen present. c) Ki-67 IHC showing all cells are expressing Ki-67. 


\begin{tabular}{|c|c|c|c|c|c|}
\hline $\begin{array}{c}\text { Growth } \\
\text { Environment }\end{array}$ & $\begin{array}{c}\text { Tested } \\
\text { Biomaterial } \\
\text { Concentration } \\
(\mathrm{mg} / \mathrm{ml} \text { or \%*) }\end{array}$ & $\begin{array}{c}\text { Min, } \\
\text { Biomaterial } \\
\text { Concentration } \\
\left(\mathrm{mg} / \mathrm{ml} \text { or } \%{ }^{*}\right)\end{array}$ & $\begin{array}{l}\text { Tested } \\
\text { Cell } \\
\text { Seeding } \\
\left(\mathrm{X} 10^{3}\right)\end{array}$ & $\begin{array}{l}\text { Min. } \\
\text { Cell } \\
\text { Seeding } \\
\left(X 10^{3}\right)\end{array}$ & $\begin{array}{c}\text { Cell } \\
\text { Distribution } \\
\text { (Side View) }\end{array}$ \\
\hline Myogel & $\begin{array}{c}N / A \\
0.5,1.3,2.6\end{array}$ & $N / A$ & \multirow{4}{*}{$\begin{array}{c}50 \\
150 \\
250\end{array}$} & 150 & $\begin{array}{l}\text { Bottom of } \\
\text { Well }\end{array}$ \\
\hline Matrigel & $0.5,2.0,4.0$ & 3.0 & & 250 & \multirow{3}{*}{ Whole Well } \\
\hline GrowDex & $0.2^{\star}, 0.5^{\star}, 1.0^{\star}$ & $0.5^{*}$ & & 250 & \\
\hline $\begin{array}{l}\text { Myogel+ } \\
\text { GrowDex }\end{array}$ & $3.0 \& 0.5^{\star}$ & $3.0 \& 0.5^{*}$ & & 250 & \\
\hline
\end{tabular}

Supplementary Table 1. Recommended Minimal Densities of Biomaterials or Cells. 